\title{
Cidade e cidadãos: 100 anos destruindo os rios paulistanos RICARDO TOLEDO NEDER
}

U M SÉCU Lo de destruição dos rios na área metropolitana de São Paulo enxovalha nossa civilidade, esmaga o perfil do cidadão, espezinha a consciência do morador da maior cidade da América do Sul, assim como destrói a saúde e a vida de milhares de habitantes pobres em áreas de risco e favelas. H á uma relação complexa de afinidades, causalidades e conflitos. Entretanto, igualmente ricos e pobres poluem os rios metropolitanos com suas águasservidas e esgotos não tratados. M ais grave é o estado-da-ar te da política pública de saneamento, que praticamente se arrasta diante da velocidade da destruição de matas nos mananciais, do lixo nas águas, esgotos clandestinos das indústrias e comunidades nas represas metropolitanas.

Esse quadro desgosta a todos invariavelmente e também causa indignação a estrangeiros que percorrem a cidade. Q uestões complexas envolvem a gestão das águas na área metropolitana de São Paulo. D aí a necessidade de compreensão das possibilidades e limites de funcionamento do Comitê da Bacia do Alto Tietê - colegiado criado em 1994 para reunir representantes de entidades associativas e profissionais, técnicos e universidades, prefeituras e membros do governo estadual, para decidir sobre projetos e obras, serviços e, sobretudo, tomar decisões para encaminhar as políticas públicas que ajudem a salvar os grande rios Tietê, Pinheiros, Tamanduateí, Pirajussara, entre outros.

O Comitê foi subdividido na Cabeceira (nascente do Tietê), e no caudal enxovalhado ao longo da zona leste até Pirapora do Bom Jesus (PinheirosPirapora). Tem ainda dois braços laterais em direção meridional: Cotia-Guarapiranga e o Tamanduateí-Billings (enormes massas d'água outrora de entretenimento e moradia contaminadas ao longo dos últimos 50 anos por indústrias e bairros, governos e cidadãos). 0 maior responsável foram as empresas do setor elétrico que não trataram das represas como patrimônio cultural e natural. 0 quinto subcomitê é o das nascentes da C antareira, ao norte, cujo adensamento urbano não deixa dúvidas dos perigos de destruição de nascentes, e dos canais que transportam águas de longe, da bacia do Piracicaba para abastecer São Paulo.

Desde 1996 o Comitê da Bacia do Alto Tietê atrai os representantes da sociedade civil (menos da econômica, que resiste em participar do comitê) com o intuito de deliberar com prefeituras e Estado sobre as coordenadas necessárias para o acompanhamento das decisões que possam salvar os rios da G rande São Paulo. 


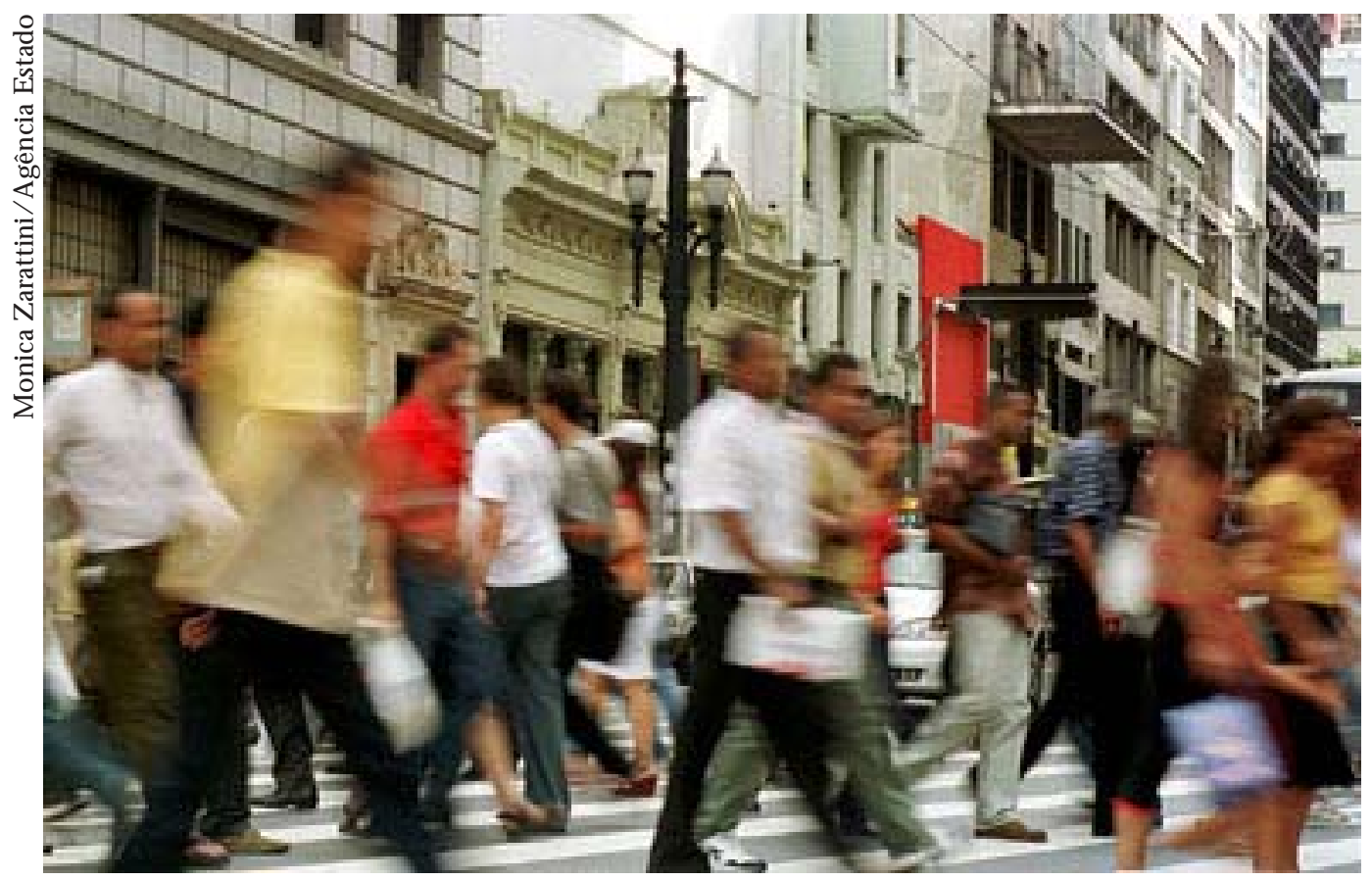

O vai evem de pedestres no centro da capital paulista ( praça R amos de A zevedo)

Esse tipo de colegiado é fruto da democracia juvenil que temos. N ão é o melhor arranjo ainda mas poderá vir a sê-lo em futuro próximo. 0 poder de informação e de intervenção dos atores econômicos e dos técnicos governamentais é muito maior que os da sociedade civil (moradores-consumidores e associações civis não-econômicas).

É dessa desigualdade que nasce o problema da capacidade governativa do comitê para alterar políticas de governos locais ( planos urbanos ezoneamento que desrespeitam as microbacias e aterram curso d'águas, ausência de planos de moradia populares) e dos governos estadual e federal (traçados de grandes obras rodoviárias que atropelam os mananciais aterram curso d'água e matam os rios).

No início dos anos de 1990, a nova política estadual de recursos hídricos surgiu diante da pressão social e política que levou à criação dos comitês de bacia. Isso rompeu a tradição no setor, controlado pelos interesses do setor elétrico e do capital industrial. Estes encaravam o aproveitamento energético dos recursos hídricos no Brasil, especialmente na região metropolitana de São Paulo e em particular no sistema Guarapiranga/ Billings/ Cubatão na Bacia do AltoT ietê, como uma questão de economia defronteira, à espera de uma exploração sem limites Com isso, todos os demais aspectos que não diziam respeito à utilização abundante do recursos para gerar eletricidade eram desconhecidos ou alijados, sob o pressuposto de que podiam ser atendidos com relativa facilidade. A bastecimento de água potável, controle e preservação da qualidade dos 
mananciais, tratamento de águas residuárias e das inundações, além de políticas de saneamento ambiental e sanitário para indústrias e prefeituras passaram por soluções técnicas que tornaram essas dimensões subordinadas à conservação e ampliação do complexo hidro-energético.

Cem anos de desperdício. Cem anos de políticas de águas no Estado que os comitês de bacia deverão enfrentar. $D$ aí a importância da pesquisa nas $C$ iências Sociais e H umanas, pois é muito árdua essa missão.

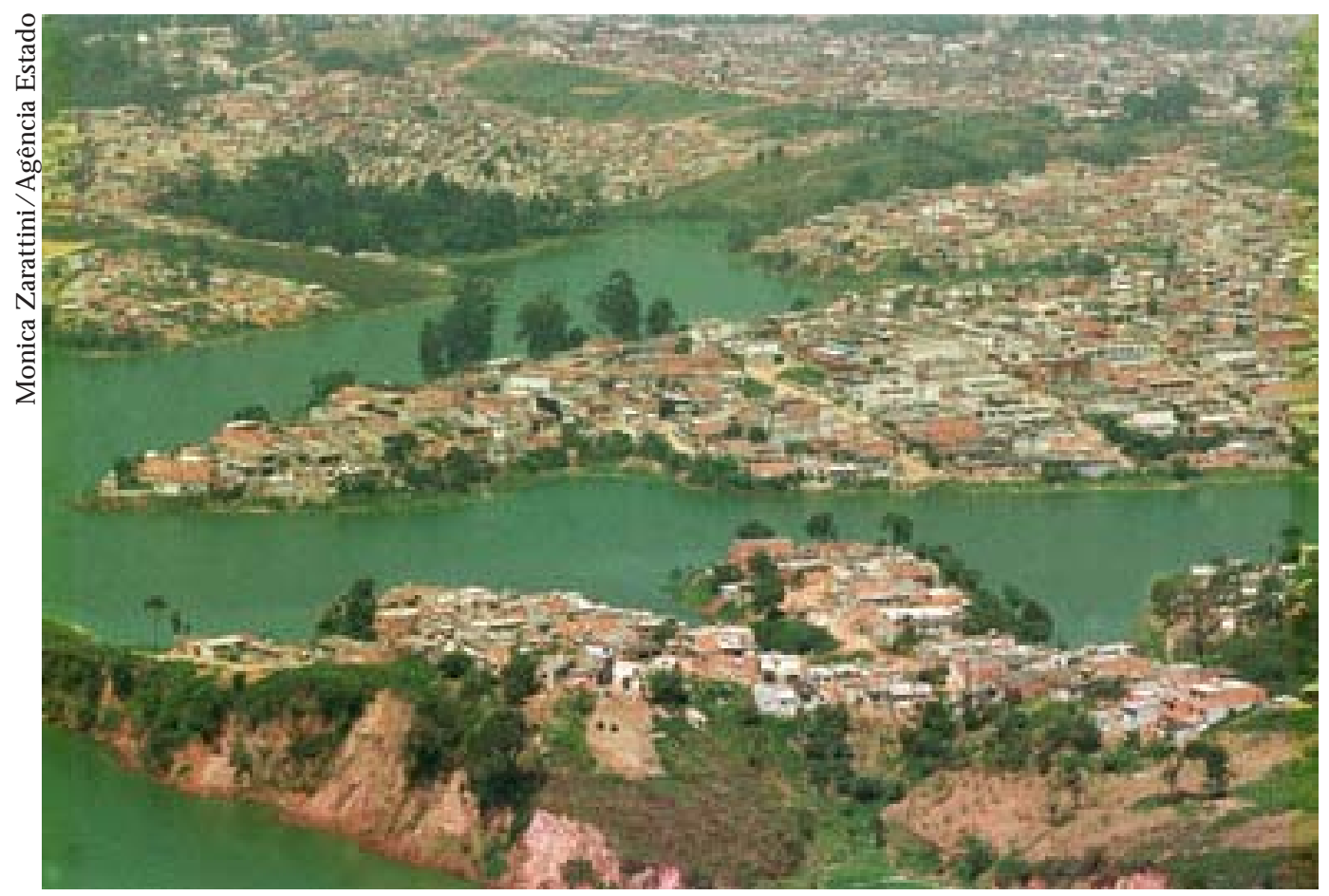

A ocupação desordenada se espalha pela região da Billings e resulta em sérios problemas

Numa avaliação político-sociológica e institucional há pelo menos três dimensões-chave que envolvem a preparação dos representantes do Comitê para aumentar sua capacidade de atuação governativa, analisadas a seguir.

- O esforço de membros de entidades da sociedade civil, das prefeituras e do Estado para trabal har como cada interesse identifica os modos de apropriação da água (acesso) e repartição de recursos. Trata-se de chegar a uma unidade de gestão das águas na região metropolitana. Poucos participantes dos comitês sabem como se dá a apropriação dos recursos hídricos pelos seus respectivos segmentos. U ma das conclusões da nossa pesquisa refere-se à necessidade de capacitar representantes e dirigentes de entidades civis e prefeituras no tocante ao desenvolvimento de modos alternativos de apropriação dos recursos hídricos na bacia.

- A segunda dimensão diz respeito ao funcionamento do processo de tomada de decisão. Grupos e indivíduos interagem no processo de decisão 


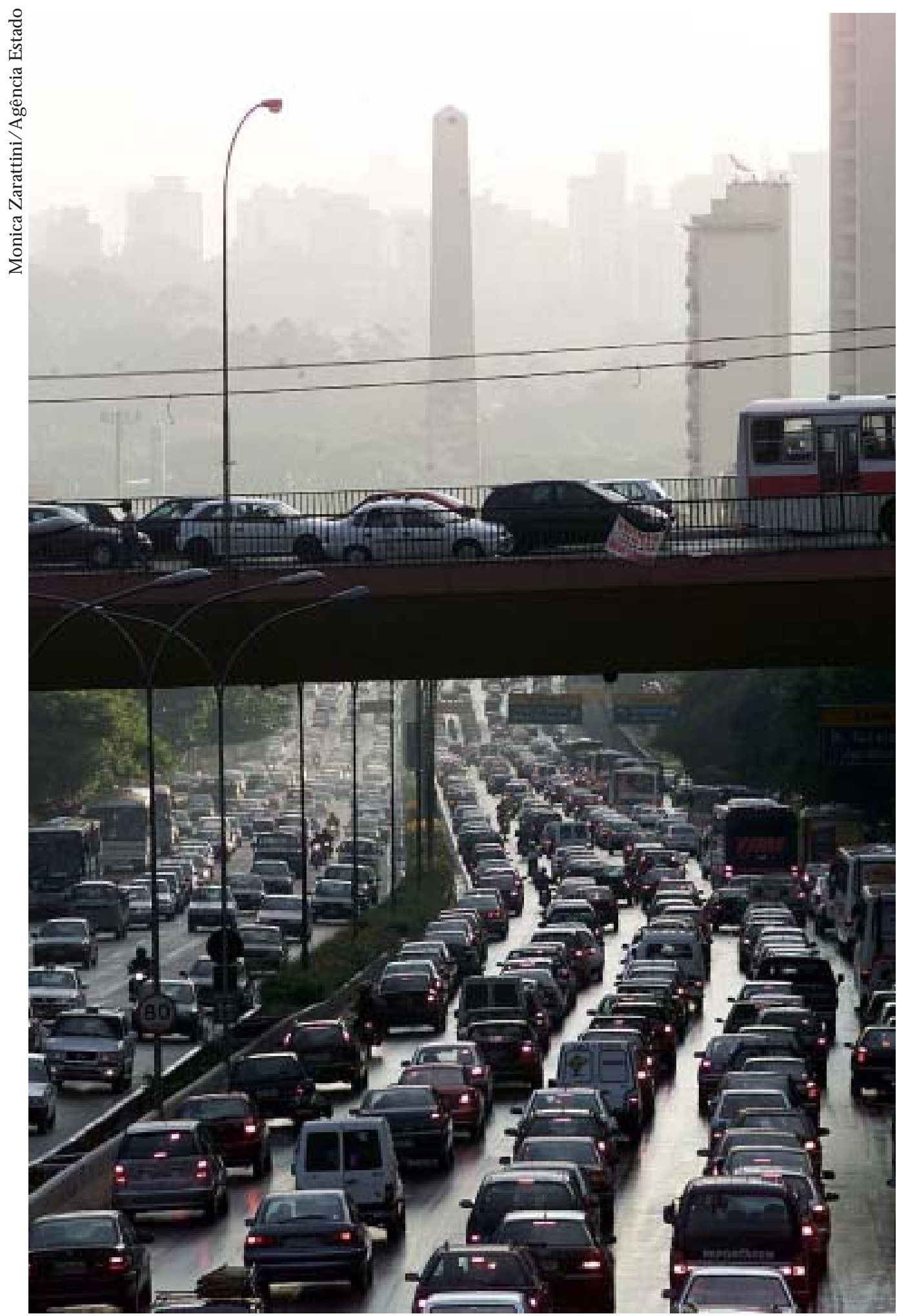

Trânsito na 23 de Maio, uma das aveni das mais movi mentadas de São Paulo. 
sobre aspectos que influirão na gestão de recursos renováveis? Como poderão obter daí melhores parcelas ou decisões? G rande parcela dos representantes de entidades civis e das prefeituras cansa-se facilmente diante do excesso de reuniões, procedimentos, discussões e manobras necessárias (ou não) para conduzir as posições em conflito e chegar a certas posições. Em geral, as partes mais fortes tentam vencer pelo cansaço. O s comitês serão efetivamente canais de coordenação e de definição de agenda política so bre as águas quando cada segmento (prefeituras, sociedade civil e governo estadual) tiver suas posições expostas e dúvidas dirimidas, o que facilita a explicitação de conflitos e agiliza a possibilidade de decisões.

- A terceira dimensão diz respeito à simulação dos modos de apropriação e de tomada de decisão (é o estágio avançado do processo de gestão sob o qual as partes envolvidas chegam a arranjos transitórios ou simulados, com base em modelização e outros, acerca dos modos de coordenação entre si na exploração de um recurso renovável). Planos de bacia ou de proteção ambiental são uma simulação dos modos de apropriação e de tomada de decisão capazes de gerar arranjos provisórios. Assemelham-se a uma carta de navegação para os atores envolvidos buscarem definir princípios e diretrizes so bre gestão compartilhada de mananciais metropolitanos (rompendo o modelo autocrático dos anos de 1970). D ada a assimetria de poder entre as prefeituras e o governo, poucas secretarias municipais têm possibilidade de desenvolver seus próprios planos de proteção ambiental, ficando à mercê de definições dos grupos técnicos estaduais. $\mathrm{N}$ enhum plano de bacia poderá ser bem recebido pelos muncípios e sociedades locais nas sub-bacias se não prever a distribuição dos recursos financeiros do fundo público de águas (Fehidro) destinados a desenvolver a capacidade de governo local e legislação específica municipal para saneamento ambiental, urbanização de favelas e habitação.

\section{Referências Bibliográficas}

AB'SAber, A. N. e PLAnten berg, C. (1996). Previsão de impactos São Paulo, Edusp.

ALVES, A. C. (1998). Saneamento básico ( concessões, permi ssões e convênios públicos). Bauru, Edipro.

BARTH , F. T. et alli. (1987). M odel os para gerenciamento de recursos hídricos São Paulo, $\mathrm{N}$ obel/ ABRH .

CESAR NETO, J. C. (1988). Política de recursos hídricos - instrumento de mudança. São Paulo, Pioneira.

CH ESN AIS, F. (1994). La mondialisation du capital. Paris, Syros.

Comitê da Bacia H idrográfica do Alto Tietê (2000) - "Economia, uso racional e reuso da água". São Paulo, CBH AT, D ocumenta 5. 
Comitê da Bacia H idrográfica do Alto Tietê (2000) - "U rbanização e inundações". São Paulo, CBH AT.

Comitê da Bacia H idrográfica do Alto Tietê (1999) - "Relatório da situação de recursos hídricos". São Paulo, CBH AT, nov.

Comitê da Bacia H idrográfica do Alto Tietê(1998) - "Q ualidade das águas na bacia do Alto Tietê: situação atual e perspectivas". São Paulo: CBH AT, D ocumenta 3, workshop, nov.

DEAN, W. (1996). A ferroefogo. A história ea devastação da M ata A tlântica brasileira. São Paulo, Companhia das Letras.

J O NAS, H . (1995). Le principe responsabilité. U ne éthique pour la civilisation technologi que. Trad. do alemão: J ean G reisch. Paris, Cerf.

KO WARICK, L. "Produção do espaço urbano e lutas sociais". In: KOWARICK, L ucio. Escritos U rbanos São Paulo, v. 34.

LANN A, A. E. L. (1995). Gerenciamento de bacia hidrográfica: aspectos conceituaise metodol ógi cos. B raślia, Instituto Brasileiro do M eio Ambiente e dos R ecursos $\mathrm{N}$ aturais.

NEDER, R. T. (2000). A valiação da capacidade governativa do Comitê de Bacia H idrográfica M etropolitana (um caso exemplar em São Paulo). D ocumento de pesquisa. Piracicaba, U SP/ ESAL Q . Programa Políticas Públicas, Fapesp, Fase.1

REBO U ÇAS, A., BRAGA, B. e TUNDISI, J. G. (1999). Á guas doces no Brasil. São Paulo. IEA-Edusp-Escrituras.

RO CH A, G. A. (1997). 0 sistema de getão daságuasem São Paulo. São Paulo, Programa Guarapiranga/ U niversidade de Campinas - U GP/ Inst. Economia. Série Textos Didáticos (I ) . Curso Extensão G estão Pública “Políticas I ntegradas de G estão A plicadas a Bacias H idrográficas",

REYD ON , B. P. (1997). "A interseção dos mercados de terras rurais e urbanos: uma proposta para a compreensão da dinâmica econômica da bacia da Guarapiranga". São Paulo, Programa Guarapiranga/ U niversidade de Campinas - U GP/ I nst. Economia. Série Textos Didáticos (I). Curso Extensão Gestão Pública "Políticas Integradas de Gestão A plicadas a Bacias H idrográficas".

RU TKO WSKI, E. (1999). "Bacia hidrográfica e bacia ambiental". São Paulo, Caderno especial Sabesp (brochura).

SACH S, I . (1986). Ecodesenvolvimento - crescer sem destruir. São Paulo, Vértice.

SAN TOS, M . (1993). A urbanização brasileira, São Paulo, H ucitec.

VILLAÇA, F. (1998). Espaço intra-urbano no Brasil. São Paulo: Studio N obel-FapespLincoln Institute.

"Experiência nacional e internacional de gestão integrada". (1991). In: Gestão integrada dos recursos ambientais, hídricos e sanitários. São Paulo, Fundap/ Seminário técnico, jan. pp. 43-61.

R icardo Toledo N eder é sociólogo doutor (U SP, 1994), pesquisador associado ao Laboratório de Silvicultura Tropical (ESALQ -U SP), onde coordena o projeto C apacitação de Representantes da Sociedade Civil e Prefeituras no Comitê da Bacia do Alto Tietê. É autor de Crise socioambiental, Estado e sociedade civil no Brasil (1982-1998) (São Paulo, Annablume, 2002). 